\title{
Surface and subsurface characterisation in micro-milling of monocrystalline silicon
}

\author{
Dehong Huo ${ }^{1,2} \cdot$ Chao Lin $^{2} \cdot$ Zi Jie Choong ${ }^{1} \cdot$ Ketan Pancholi $^{1} \cdot$ Patrick Degenaar $^{3}$
}

Received: 23 March 2015 / Accepted: 11 May 2015 / Published online: 21 May 2015

(C) Springer-Verlag London 2015

\begin{abstract}
This paper presents an experimental investigation on surface and subsurface characterisation of micro-machined single-crystal silicon with (100) orientation. Full immersion slot milling was conducted using solid cubic boron nitride (CBN) and diamond-coated fine grain tungsten carbide micro-end mills with a uniform tool diameter of $0.5 \mathrm{~mm}$. The micro-machining experiments were carried out on an ultra-precision micro-machining centre. Formal design of experiments (DoE) techniques were applied to design and analysis of the machining process. Surface roughness, edge chipping formation and subsurface residual stress under varying machining conditions were characterised using white light interferometry, SEM and Raman microspectroscopy. Tens of nanometre-level surface roughness can be achieved under the certain machining conditions, and influences of variation of cutting parameters including cutting speeds, feedrate and axial depth of cut on surface roughness were analysed using analysis of variance (ANOVA) method. Raman microspectroscopy studies show that compressive subsurface residual stress and amorphous phase transformation were observed on most of the micro-machined subsurface, which provides evidence of ductile mode cutting. Surface and subsurface characterisation studies show that the primary material removal mode is ductile or partial ductile using lower feedrate for both tools, and
\end{abstract}

Dehong Huo

dehong.huo@newcastle.ac.uk

1 School of Mechanical and Systems Engineering, Newcastle University, Newcastle Upon Tyne NE1 7RU, UK

2 The State Key Laboratory of Mechanical Transmission, Chongqing University, Chongqing 400044, China

3 School of Electrical and Electronic Engineering, Newcastle University, Newcastle Upon Tyne NE1 7RU, UK diamond-coated tools can produce better surface quality. Silicon brain implants were fabricated with good dimensional accuracy and edge quality using the optimised machining conditions, which demonstrated that micro-milling is an effective process for fabrication of silicon components at a few tens to a few hundreds of micron scale.

Keywords Micro-milling · Monocrystalline silicon · Ductile mode cutting $\cdot$ Subsurface residual stress $\cdot$ Machining-induced edge chipping $\cdot$ Diamond tool

\section{Introduction}

The need to fabricate high-accuracy miniature components with dimensions ranging from several hundred microns to several millimetres or features ranging from several to several hundreds of microns has encouraged research on development of micro-manufacturing processes. It is well recognised that micro-manufacturing has been a key enabling technology in industries producing useful micro-components and products [1-3]. Amongst various engineering materials for micro-products, semiconductor materials such as silicon are playing a significant role in certain applications. Typical area of applications for micro-silicon components includes MEMS, microfluidics and opto-electronics.

Traditionally, clean room approaches, such as lithography and chemical etching, dominate the fabrication of semiconductor components. Due to the nature of such processes, lithography-based processes possess a number of constraints such as planar 2 or 2.5 dimensional process with low relative accuracy and poor surface finish. In addition, these processes are only economical for large production scale due to high investment cost for prototyping [3]. To overcome these constraints, improvement on traditional lithography-based 
processes and development of alternative micro-manufacturing processes are being investigated.

Micro-milling, an emerging micro-manufacturing process, has been successfully applied in fabrication of 3D complex shape micro-components with excellent dimensional accuracy and surface finish over various engineering materials, including metals such as aluminium [4-6], copper [7-9], titanium alloys [10, 11], steels [12,13], graphite [14], tungsten carbides [15], polymers [16, 17] and composites [18]. Recently, it has been applied in machining brittle materials and crystals [19-23] with success. Micro-milling is therefore expected to have the potentials to cost effectively fabricate complexshaped silicon micro-components with feature size at the order of several tens to several hundreds of microns. Success of micro-milling of silicon will open new industrial avenues in fabrication of silicon-based micro-products because of its capability of producing true 3D complex-shaped micro-products with high accuracy and good surface finish. In addition, it fills the gap of fabrication of micro/mesoscale components for prototype or small batch production. Silicon being a brittle material poses challenges on achieving a machined surface with minimum defects. Currently, insufficient experimental data available on characterisation of micro-machined silicon surface limits its industrial application. Hence, the objective of this research is to perform micro-milling experiment using various micro-tools to investigate surface and subsurface generation mechanism.

Organisation for the remainder of this paper is as follows: Firstly, Section 2 reviews the ductile model machining of brittle material and micro-milling of silicon. The experimental set-up as well as machining and measurement procedure is then described in Section 3. Surface topography, surface roughness, edge chipping and residual stress measurement results are presented and discussed both qualitatively and quantitatively in Section 4. Following in Section 5 is an application perspective of micro-milling of silicon. Finally, conclusions drawn from this research are given in Section 6.

\section{Ductile mode machining of silicon}

Brittle materials, such as silicon, can be deformed plastically in machining, i.e. ductile mode machining under a highly compressive hydrostatic pressure in the cutting zone. The highly compressive hydrostatic pressure can suppress the crack propagation and promote plastic deformation, i.e. dislocation motion. Another enabling factor of ductile mode machining of brittle materials is very small uncut chip thickness and depth of cut. It is believed that there is a critical uncut chip thickness, below which the energy required to cause fracture is higher than that required for plastic deformation so that plastic deformation becomes the primary mechanism of material removal $[24,25]$. Possibility of machining brittle materials in the ductile mode has been demonstrated in single-point diamond turning (SPDT) of silicon [26-28]. This normally involves an extremely rigid ultra-precision machine tool with aerostatic or hydrostatic bearing slideways and spindle. In addition, single-crystal diamond tool with large negative tool rake angle is also required.

Although numerous reports had described the experimental studies related to diamond turning of silicon, however, from the micro-cutting mechanics point of view, some issues such as intermittent processes, instantaneous changing uncut chip thickness and high-frequency dynamic cutting forces make micro-milling process much more complex compared with SPDT. Machining conditions for ductile mode machining of silicon optimised from conventional ultra-precision machining cannot be used directly in micro-milling. Currently, investigations on micro-milling of single-crystal silicon are limited; notably, Rusnaldy et al. [19, 20] performed micro-end milling of single-crystal silicon using diamond-coated end mills of $\Phi 0.178 \mathrm{~mm}$. Both cutting force and surface quality were examined during experiments, and the results show a critical value of feed per tooth for ductile mode of single-crystal silicon. Although nanometre levels of surface roughness Ra were obtained, extreme small feed per tooth (a few nanometers) and axial depth of cut (less than 1 micron) employed in their experiments are not comparable to its advantage over traditional lithography-based process. Arif et al. reported experimental results of micro-ball end milling of silicon and suggested that titled end milling can improve surface finish. Fifteenmicrometer deep fracture-free slots were machined when a critical feedrate was maintained [21]. Cheng presented an experimental investigation on micro-machining of silicon using $\Phi 0.5-\mathrm{mm}$ micro-grinding pin. A very wide feedrate range was employed to study the unformed chip thickness on the cutting mode, and a critical value to obtain ductile mode cutting was determined [29].

Numerical simulations were also performed on microcutting of silicon. Finite element method is effective for metals as the material models have been developed to describe relations between flow stress and strain, strain rate and temperature. However, no effective material models can be used to model brittle materials. On the other hand, molecular dynamic (MD) simulation can simulate the pressure-induced phase transformation, hence explains the phenomena in cutting of silicon [30, 31]. However, current state-of-the-art in MD simulation of cutting process limits its space scale in tens of nanometres for 3D simulation or hundreds of nanometres for 2D simulation. Therefore, it is only applicable to investigating nanometric cutting. Due to these limitations with simulation approaches, experimental investigation on micro-cutting of silicon is necessary. At present, insufficient experimental data from various micro-tools and machining conditions limits industrial applications of micromilling of single-crystal silicon. 
Large negative rake angle single-crystal diamond tools are widely used in turning of silicon to apply compressive stress in the zone. Due to a small diameter and complex geometry of micro-end mills, commercial end mills cannot be manufactured with a large negative rake angle. However, when uncut chip thickness is on the same order as tool edge radius, the effective rake angle may become negative. This is known as the cutting edge radius size effect.

The cutting edge radius size effect in a micro-cutting can be modelled by determining an equivalent shearing plane and calculating an equivalent rake angle. The effective rake angle in micro-cutting can be defined as the plane tangent to the edge radius at a distance from the machined surface corresponding to the uncut chip thickness, $h$, as shown in Fig. 1. There is a critical value of the uncut chip thickness, $h_{\mathrm{c}}$, above which chip sliding occurs on the nominal rake face. The effective rake angle, $\alpha_{t}$, is expressed by

$$
\begin{array}{cl}
\alpha_{t}=\arcsin \left(\frac{h}{R_{\varepsilon}}-1\right) & \text { for } h<h_{c} \\
\alpha_{t}=\alpha & \text { for } h>h_{c}
\end{array}
$$

where $R_{\varepsilon}$ is the cutter edge radius, $\alpha$ is the nominal rake angle and $h_{\mathrm{c}}$ is given by $h_{\mathrm{c}}=R_{\varepsilon}(1+\sin \alpha)$. The cutting edge radius of the end mills measured in this research is at the order of several microns. Hence, by choosing a proper uncut chip thickness, the cutting edge radius size effect can be utilised in micro-milling to enable ductile mode cutting of silicon.

\section{Experimental set-up}

\subsection{Machine tool}

Experiments for this work were carried out on an ultraprecision desktop micro-machining centre (Nanowave MTS5R). The machine is equipped with a high speed spindle offering a continuous power output of $350 \mathrm{~W}$ and an output torque of $3 \mathrm{cNm}$ over the speed range of 20,000 to 80 ,
$000 \mathrm{rpm}$. The high speed spindle allows a reasonable higher cutting velocity even when small-diameter cutters are used. Ultra-precision collets were used to clamp the micro-end mills and the spindle runout was controlled within $1 \mu \mathrm{m}$. The XYZ slideways provide a precision of $0.1 \mu \mathrm{m}$. This experimental set-up ensures that both the main spindle errors such as vibration and run-out, and slideway inaccuracy were minimised. Therefore, the main spindle and slideway errors on surface quality will not be explicitly taken into account in the analysis. The experimental set-up is illustrated in Fig. 2.

\subsection{Silicon workpiece preparation}

Silicon wafers used in this study were 4 in. in diameter and 0.5 -mm-thick single-crystal silicon wafer with epitaxy ready polished to a surface roughness, $\mathrm{Ra}$, of $0.5 \mathrm{~nm}$. The sample is a type $p$ wafer with (100) crystal orientation. The wafer was diced into $15 \mathrm{~mm} \times 15 \mathrm{~mm}$ square pieces, and the square wafer was adhesively boned onto a ground aluminium fixture. During machining, the cutting tool is fed along [100] direction. Perpendicularity between the wafer surface and the cutting tool axis was carefully adjusted before the machining experiments to ensure a uniform axial depth of cut.

\subsection{Micro-end mills}

Two types of micro-square end mills, namely cubic Boron Nitride (CBN), diamond-coated tungsten carbide (DC) micro-end mills, were used in the experiments. Both tools have a same nominal diameter of $0.5 \mathrm{~mm}$. A uniform tool shank diameter of $3 \mathrm{~mm}$ is used for all micro-tools to fit 3$\mathrm{mm}$ ultra-precision spindle collet. A relative large tool diameter was selected in the experiments to avoid premature tool breakage in those aggressive cuts and hence ensures that excess tool chipping and wear on all tools were minimised. Table 1 lists the geometries of micro-end mills used in the experiments. The cutting edge radius was measured on the cross-sectional SEM images by fitting a circle, as illustrated in Fig. 3. The estimated values are 3 and $6 \mu \mathrm{m}$ for $\mathrm{CBN}$ and
Fig. 1 Equivalent shearing plane and effective rake angle
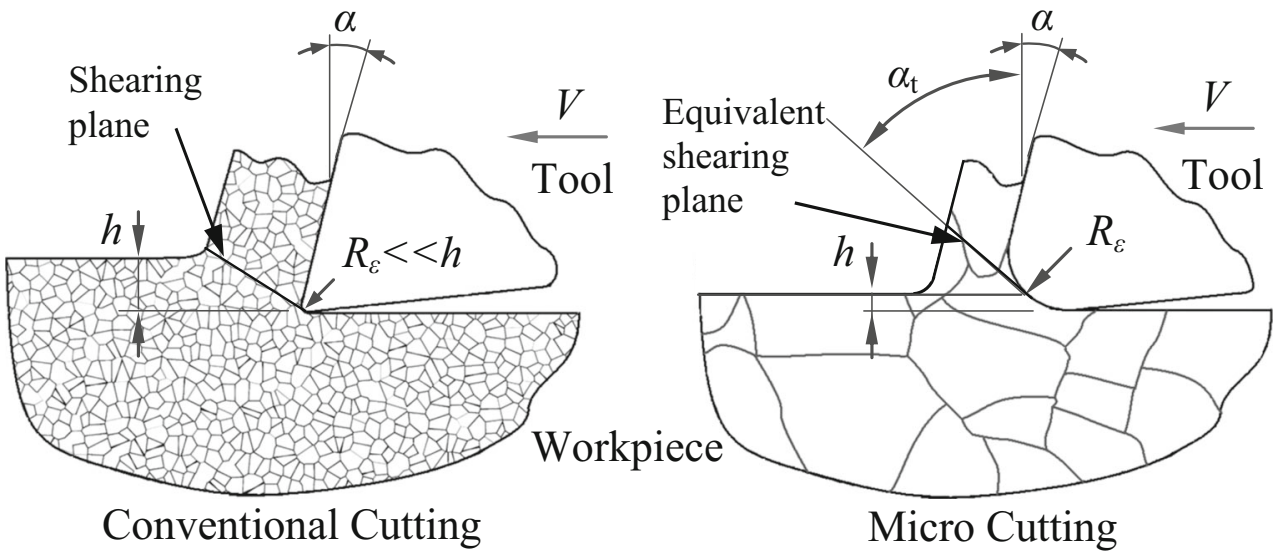


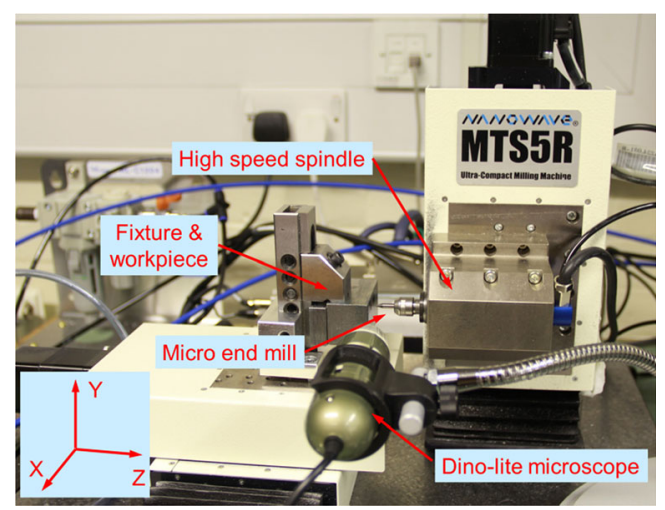

Fig. 2 Experimental set-up for micro-milling of silicon

diamond coated, respectively. It should be noted that some tool parameters of CBN and diamond tools, such as helix angle, flute length and rake angle, are slightly different. Due to the small feedrate (sub-microns per tooth) and depth of cut $(10 \mu \mathrm{m}, 30 \mu \mathrm{m})$ used in this experiment, the influence of these tool parameters on the machined surface was not taken into consideration.

\subsection{Experimental procedure}

The experiments in this work include full immersion slot milling. For each test, a 5-mm long and $0.5-\mathrm{mm}$ wide micro-slot was milled along [100] direction. The levelness of the square silicon wafer surface to the cutting tool axis was firstly adjusted carefully using a $1-\mu \mathrm{m}$ resolution dial gauge, and less than 5 - $\mu \mathrm{m}$ levelness deviation was obtained over the $15 \mathrm{~mm} \times$ $15 \mathrm{~mm}$ machining area. To eliminate the levelness deviation effect on the depth of cut, NC programme ( $Z$ feed) was also adjusted to compensate this geometric errors thanks to the $0.1-\mu \mathrm{m}$ feed resolution of the machine tool. Zero position of the cutting tool relative to silicon wafer surface was set with assistance of a machine vision system (Dino-lite microscope) and initial contact test using a Kistler dynamometer under a very slow feedrate. This setting up procedure allows machining with micrometric depth of cut.

Table 1 Geometries of micro-tools used in the experiments

\begin{tabular}{lll}
\hline & CBN & Diamond coated \\
\hline Nominal diameter $(\mathrm{mm})$ & 0.5 & 0.5 \\
No. of flute & 2 & 2 \\
Helix angle $\left({ }^{\circ}\right)$ & 20 & 25 \\
Flute length $(\mathrm{mm})$ & 1.5 & 1 \\
Nominal rake angle $\left(^{\circ}\right)$ & 0 & -5 \\
Clearance angle $\left(^{\circ}\right)$ & 12 & 10 \\
Nominal Corner radius $(\mathrm{mm})$ & 0 & 0.05 \\
Tool edge radius $(\mu \mathrm{m})$ & 3 & 6 \\
\hline
\end{tabular}

Dry machining was performed to avoid contamination, and air blow was used throughout the machining experiments to reduce the possibility of chip jam-induced microcracks. Three controlled quantitative factors used in the experiments are cutting speed $(\mathrm{m} / \mathrm{min})$, feedrate ( $\mu \mathrm{m} /$ tooth) and axial depth of cut $(\mu \mathrm{m})$. Because there are only three controlled factors considered for each type of micro-tools in the experiments, full factorial experimental designs were implemented to capture all of the main effects and their interactions. Two levels of cutting speed and depth of cut were selected, albeit four levels of feedrate were selected. The $4 \times 2 \times 2$ mixed level full factorial design matrix is presented in Table 2 . Each set of cutting parameter was repeated once to reduce machining errors and separate effect due to interactions from measurement noise. A total of 32 slots were machined for each cutter. In order to reduce the influence of tool wear on the surface quality and edge chipping, brand new micro-tools were used for the experiments. Extra slots (Exp \#17, see Table 2) were milled at the end of experiments using the same cutting conditions as Exp \#1 (see Table 2). This validation slot was then compared with the first slot (Exp \#1).

\subsection{Surface roughness measurement and surface morphology inspection}

After machining, the machined surface was cleaned in acetone by an ultrasonic bath. The average surface roughness of the bottom surface of the micro-milled slots was then measured using a white light interferometer (Zygo NewView 5000) along the centreline of the slots. To reduce the measurement uncertainty and assess repeatability, four measurements on different areas were conducted for each slot and an average value of surface roughness $(\mathrm{Ra})$ is used for analysis. Mean values of measured surface roughness, $\mathrm{Ra}$, are listed in Table 2. The surface morphology and edge chipping were analysed on the basis of SEM micrographs. Analysis on the response-surface roughness and morphology will be presented in Section 4.

\subsection{Raman spectroscopy}

Raman microspectroscopy has successfully been applied in the analysis of stresses induced from a variety of sources in silicon devices and other Raman active materials, such as polymers, semiconductors and ceramics [32, 33]. Recently, Raman microspectroscopy method has been used to investigate subsurface layer composition, i.e. phase transformation and residual stress in ultra-precision machining of silicon [34, 35]. However, it has yet applied to surface integrity characterisation in micro-milling.

A Horiba Jobin Yvon HR800 Raman microscope equipped with a 514-nm Ar+ion laser probe was used for residual stress measurement in this research, and a $5.2-\mathrm{mW}$ laser beam was 
Fig. 3 Cutting edge radius measurement by SEM. a Diamond-coated tool, $\mathbf{b}$ CBN tool

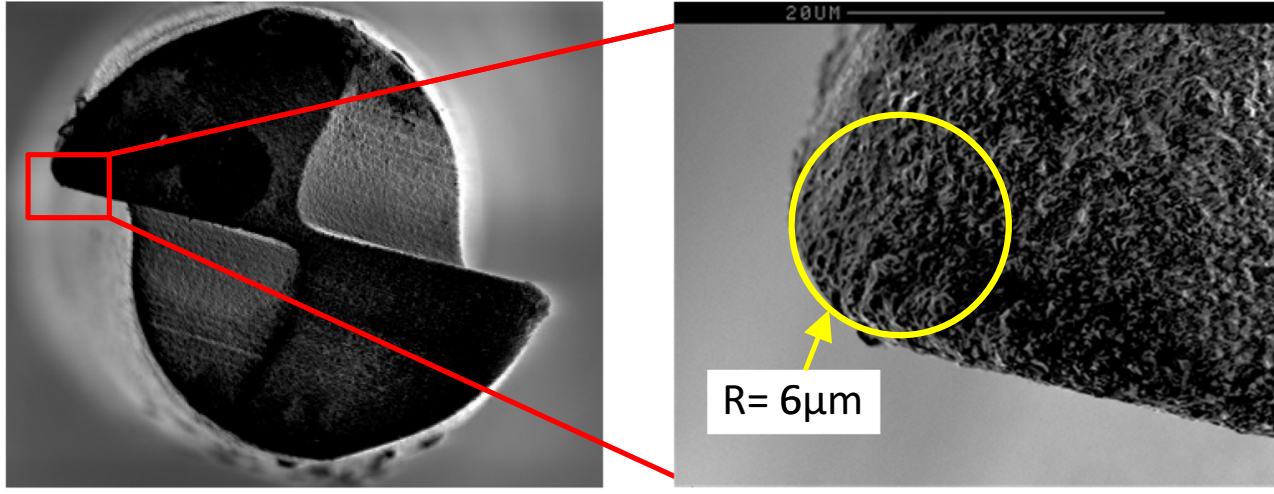

(a)

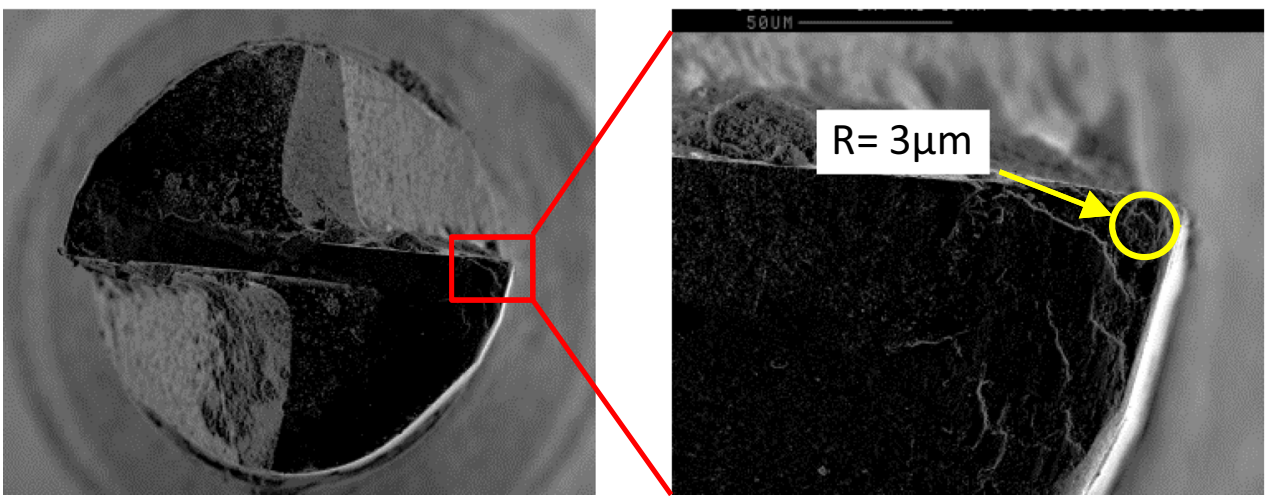

(b) delivered to the silicon surface. The low-power laser beam was used to eliminate heating effects on the measured surface. The Raman microscope comprised of a motorised XY stage which allowed for automated mapping, and a $\times 100$ objective was used to image the device and collect the Raman signal, which provided a spatial resolution of $1 \mu \mathrm{m}$. The Raman signal was passed through the spectrometer before being measured by a CCD camera and data points were collected every $0.54 \mathrm{~cm}^{-1}$. The profile was then saved to a PC. One-second static scan was employed for area scanning. The microscope was calibrated on stress-free polished silicon wafer surface before the measurements. Each point was measured four times to reduce random errors. All measurements were performed at room temperature.

\section{Results and discussions}

Both qualitative and quantitative analyses were carried out to characterise surface and subsurface properties of micro-milled silicon surface. Qualitative analysis includes edge chipping formation, cutting mode observation, surface topography and phase transformation, and quantitative analysis includes surface roughness and surface residual stresses.

\subsection{Surface topography}

Figure 4 shows the SEM micrographs on the bottom machined surface. Various types of surface defects were found on the micro-machined surface. Residual flake chips, microdebris and irregular streaks were found on some surfaces machined by diamond-coated tools and CBN tools, and micropits were also observed on CBN machined surfaces. Type and quantity of surface defects are used to characterise achieved mode of machining. Regular tiny machining marks and absence of other surface defects are the typical ductile surface texture and hence indicate that surface is under ductile mode machining (examples are Fig. 4a, b, e, f). Few surface defects left on the machined surface can be regarded as partial ductile mode machining (examples are Fig. 4c, d, i, j). Noticeable surface defects on the machined surface indicate that brittle mode machining has taken place (examples are Fig. 4k, 1, o, p).

The results show that feedrate and axial depth of cut have a significant influence on the surface generation, whilst the cutting speed was found to be not significant in determining the mode of machining. Small feedrate and axial depth of cut produce fewer surface defects and hence promote ductile mode machining. Under the same machining conditions, 
Table 2 Experimental matrix of micro-milling of silicon and responses (mean measured surface roughness, Ra, and surface residual stress)

\begin{tabular}{|c|c|c|c|c|c|c|c|c|c|c|}
\hline \multirow[t]{3}{*}{ Exp. no. } & \multicolumn{4}{|c|}{ Experimental matrix — controlled factors ${ }^{1}$} & \multicolumn{6}{|l|}{ Responses } \\
\hline & \multirow{2}{*}{$\begin{array}{l}\text { Feedrate } \\
\mathrm{fz},(\mu \mathrm{m} / \text { tooth })\end{array}$} & \multirow{2}{*}{$\begin{array}{l}\text { Cutting speed } \\
\mathrm{Vc},(\mathrm{m} / \mathrm{min})\end{array}$} & \multirow{2}{*}{$\begin{array}{l}\text { Spindle speed } \\
n,(\mathrm{rpm})\end{array}$} & \multirow{2}{*}{$\begin{array}{l}\text { Depth of cut } \\
a_{\mathrm{p}},(\mu \mathrm{m})\end{array}$} & \multicolumn{3}{|c|}{ Diamond coated } & \multicolumn{3}{|l|}{$\mathrm{CBN}$} \\
\hline & & & & & $\begin{array}{l}\text { Surface } \\
\text { roughness, } \\
\operatorname{Ra}^{2}(\mu \mathrm{m})\end{array}$ & $\begin{array}{l}\text { Surface } \\
\text { residual } \\
\operatorname{stress}^{3}(\mathrm{MPa})\end{array}$ & $\begin{array}{l}\text { Cutting } \\
\text { mode }^{4} \\
(\mathrm{D} / \mathrm{PD} / \mathrm{B})\end{array}$ & $\begin{array}{l}\text { Surface } \\
\text { roughness, } \\
\operatorname{Ra}(\mu \mathrm{m})\end{array}$ & $\begin{array}{l}\text { Surface } \\
\text { residual } \\
\text { stress, }(\mathrm{MPa})\end{array}$ & $\begin{array}{l}\text { Cutting } \\
\text { mode } \\
(\mathrm{D} / \mathrm{PD} / \mathrm{B})\end{array}$ \\
\hline 1 & 0.0375 & 31.4 & 20,000 & 10 & 0.085 & 43.8 & $\mathrm{D}$ & 0.132 & -50.6 & PD \\
\hline 2 & 0.075 & 31.4 & 20,000 & 10 & 0.081 & -15.5 & $\mathrm{D}$ & 0.197 & -120.7 & PD \\
\hline 3 & 0.15 & 31.4 & 20,000 & 10 & 0.069 & -205.3 & $\mathrm{PD}$ & 0.166 & -443.7 & $\mathrm{~B}$ \\
\hline 4 & 0.3 & 31.4 & 20,000 & 10 & 0.072 & -287.1 & PD & 0.220 & -419.3 & B \\
\hline 5 & 0.0375 & 78.5 & 50,000 & 10 & 0.048 & 15.2 & $\mathrm{D}$ & 0.053 & -63.6 & PD \\
\hline 6 & 0.075 & 78.5 & 50,000 & 10 & 0.039 & -56.8 & $\mathrm{D}$ & 0.135 & -137.1 & PD \\
\hline 7 & 0.15 & 78.5 & 50,000 & 10 & 0.039 & -311.4 & $\mathrm{D}$ & 0.212 & -520.3 & B \\
\hline 8 & 0.3 & 78.5 & 50,000 & 10 & 0.053 & -573 & PD & 0.265 & -604.5 & B \\
\hline 9 & 0.0375 & 31.4 & 20,000 & 30 & 0.080 & -70.7 & $\mathrm{D}$ & 0.150 & -219.2 & PD \\
\hline 10 & 0.075 & 31.4 & 20,000 & 30 & 0.085 & -241.3 & $\mathrm{D}$ & 0.247 & -201.4 & B \\
\hline 11 & 0.15 & 31.4 & 20,000 & 30 & 0.087 & -576.2 & PD & 0.275 & -536.6 & B \\
\hline 12 & 0.3 & 31.4 & 20,000 & 30 & 0.094 & -636.1 & PD & 0.272 & -699.5 & B \\
\hline 13 & 0.0375 & 78.5 & 50,000 & 30 & 0.053 & -112 & $\mathrm{D}$ & 0.177 & -328.3 & PD \\
\hline 14 & 0.075 & 78.5 & 50,000 & 30 & 0.062 & -228.1 & $\mathrm{D}$ & 0.155 & -447.1 & B \\
\hline 15 & 0.15 & 78.5 & 50,000 & 30 & 0.078 & -556 & PD & 0.242 & -544.1 & B \\
\hline 16 & 0.3 & 78.5 & 50,000 & 30 & 0.091 & -767.7 & PD & 0.313 & -678.8 & B \\
\hline $17^{5}$ & 0.0375 & 31.4 & 20,000 & 10 & 0.088 & 73.0 & $\mathrm{D}$ & 0.155 & -91.3 & $\mathrm{PD}$ \\
\hline
\end{tabular}

${ }^{1}$ Uncontrolled factors: width of cut, $a_{\mathrm{e}}=0.5 \mathrm{~mm}$; cutter diameter, $D=0.5 \mathrm{~mm}$; no of flutes, $Z=2$; slot length=5 mm; cutting direction [100]

${ }^{2}$ Surface roughness values presented in the table are the arithmetic mean of measured Ra values

${ }^{3}$ Positive values represent tensile residual stress and negative values represent compressive residual stress

${ }^{4} D$ denotes ductile mode; $P D$ denotes partial ductile mode; $B$ denotes brittle mode

${ }^{5}$ Validation slot, same machining condition as Exp \#1

diamond-coated tools are more likely to achieve ductile mode machining and hence better surface finish with fewer surface defects. Ductile machined surfaces have been achieved by diamond-coated tools when a small feedrate $(f z=0.0375 /$ tooth, $0.075 \mu \mathrm{m} /$ tooth) was used. The primary machining modes for CBN tools are still the brittle fracture or partial ductile under the cutting conditions in the experiments.

\subsection{Edge chipping formation}

Edge chipping is a type of surface/subsurface defect normally induced in machining of brittle materials. Machining-induced edge chipping will not only affect the geometric accuracy of finished parts but also cause the potential functional failure due to the microcracks left on the finished part [36, 37]. In micro-milling of micro-parts, the size of edge chipping defects can be comparable to the feature size; therefore, control and suppression of edge chipping formation in micro-milling becomes a pressing challenge. Figure 5 shows typical slots machined by $\mathrm{CBN}$ and diamond-coated end mills, respectively.
In a full immersion milling operation, both up milling and down milling sides of the slot are generated. In up milling, the cutting direction is opposite to the feed direction and the surface is generated at the beginning of the cut, whilst the cutting direction is the same as the feed direction in down milling and the surface is generated when the cutting edge exits the workpiece. Therefore, up milling and down milling have different characteristics in edge chipping formation.

$\mathrm{Ng}$ et al. categorised edge chipping in slot milling as entry, interior and exit chipping [37]. All three types of edge chipping have been observed in micro-milled silicon slots, albeit interior edge chipping was found the dominant chipping formed in the material removal along the tool path. However, the interior edge chipping defects were predominantly observed in the down milling side of the slot, and lesser or no edge chipping in the up milling side was formed as shown in Fig. 5. Brittle materials like silicon are more sensitive to impact at workpiece entry, and in up milling the nominal instantaneous uncut chip thickness starts from zero and increases gradually, so lesser or edge chipping defects are formed. 


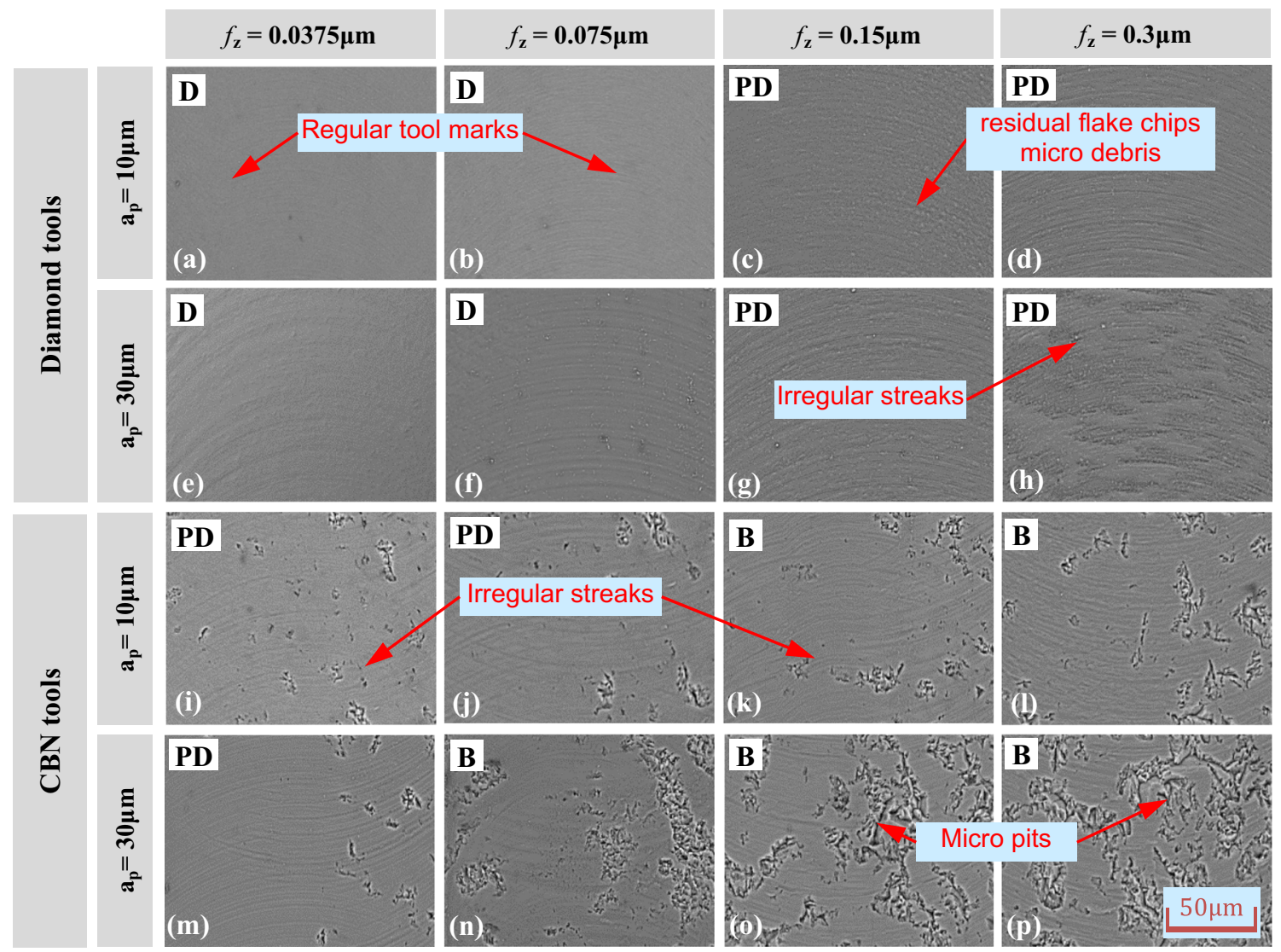

Fig. 4 Machined surface topography at different feedrates and depths of cut (cutting speed $31.4 \mathrm{~m} / \mathrm{min}$ ). $D$ ductile mode, $P D$ partial ductile mode, $B$ brittle mode

Fig. 5 SEM micrographs of micro-milled slots showing interior edge chipping. a, b Micro-slots by the CBN tool; $\mathbf{c}, \mathbf{d}$ micro-slots by the diamond tool. Cutting conditions: $\mathrm{fz}=0.075 \mu \mathrm{m} /$ tooth; $\mathrm{Vc}=31.4 \mathrm{~m} / \mathrm{min} ; a_{p}=$ $10 \mu \mathrm{m}$ in $\mathbf{a}$ and $\mathbf{c} ; a_{p}=30 \mu \mathrm{m}$ in $\mathbf{b}$ and $\mathbf{d}$

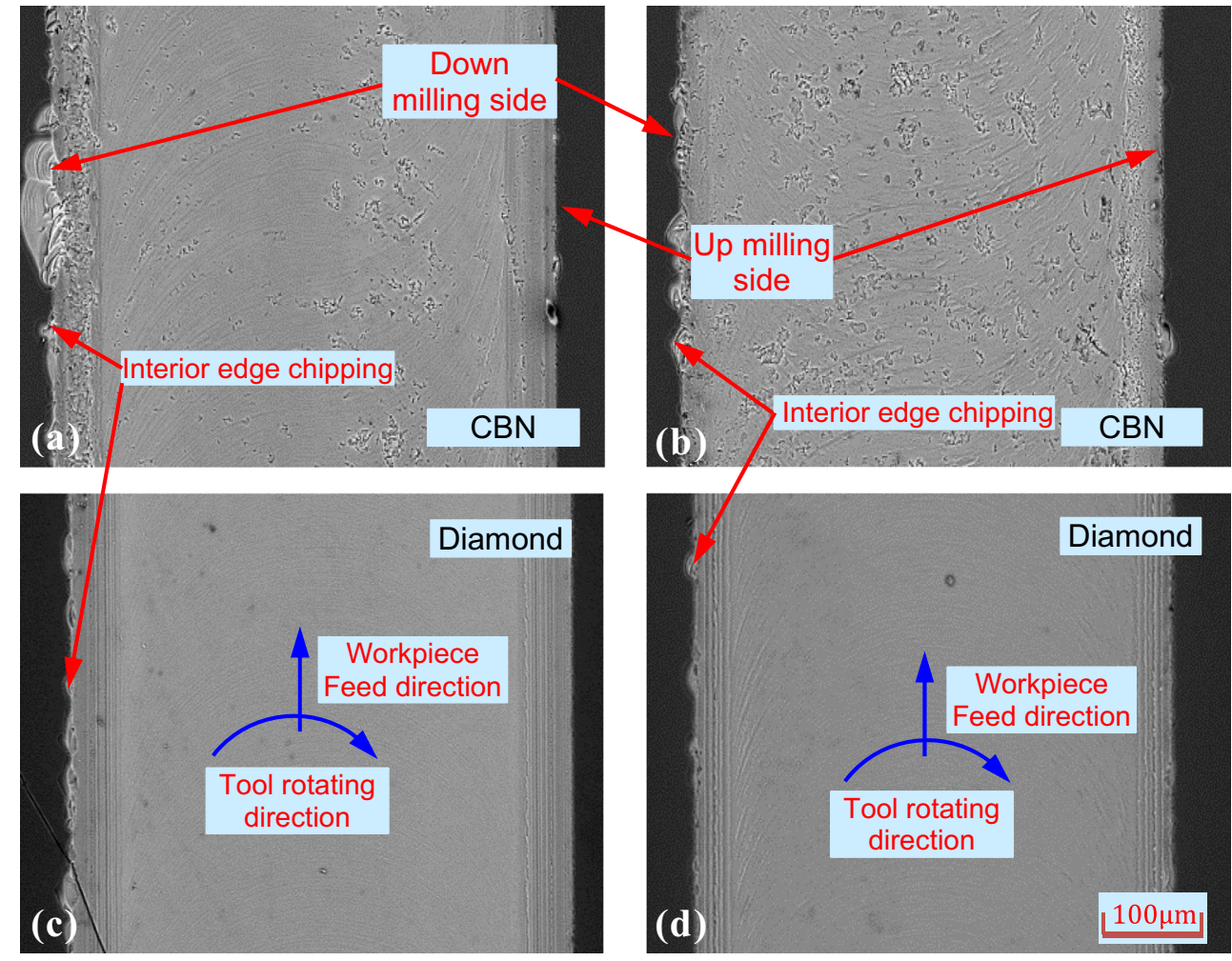


Table 3 ANOVA for surface roughness, Ra, using diamond-coated tools

\begin{tabular}{|c|c|c|c|c|c|c|c|}
\hline Source of variation & $\begin{array}{l}\text { Sum of squares } \\
\left(\times 10^{-3}\right)\end{array}$ & $\begin{array}{l}\text { Degrees } \\
\text { of freedom }\end{array}$ & $F$ (calculated) & $\begin{array}{l}F \text { (tabulated, } \\
\alpha=0.05)\end{array}$ & $P$ value & $\begin{array}{l}\text { Contribution } \\
\text { ratio } \%\end{array}$ & Result interpretation \\
\hline Feedrate (A) & 1.326 & 3 & 9.73 & 2.80 & 0.000 & 5.829 & Not significant \\
\hline Cutting speed (B) & 9.120 & 1 & 200.72 & 4.04 & 0.000 & 40.089 & Significant \\
\hline Depth of Cut (C) & 5.184 & 1 & 114.09 & 4.04 & 0.000 & 22.788 & Significant \\
\hline $\mathrm{AB}$ & 1.383 & 3 & 10.14 & 2.80 & 0.000 & 6.079 & Not significant \\
\hline $\mathrm{AC}$ & 2.349 & 3 & 17.23 & 2.80 & 0.000 & 10.326 & Not significant \\
\hline $\mathrm{BC}$ & 1.122 & 1 & 24.70 & 4.04 & 0.000 & 4.932 & Not significant \\
\hline $\mathrm{ABC}$ & 0.084 & 3 & 0.62 & 2.80 & 0.607 & 0.369 & Not significant \\
\hline Error & 2.181 & 48 & & & & 9.587 & \\
\hline Total & 22.749 & 63 & & & & 100 & \\
\hline
\end{tabular}

It is also observed that under the same cutting conditions, diamond tools tend to produce lesser edge chipping defects than CBN tools. Depth of cut has a negative effect on edge chipping formation, i.e. a depth of cut of $30 \mu \mathrm{m}$ produces relatively larger chipping than that of $10 \mu \mathrm{m}$, whilst feedrate and cutting speed have little effect on the dimension of the edge chipping defects.

\subsection{Surface roughness}

Analysis of variance (ANOVA) was performed on surface roughness data to isolate main effects of each source of variations and determine effects of interactions. Surface finish of the bottom surface of the micro-slot was measured using a Zygo white light interferometer. Arithmetic surface roughness, Ra, which provides information of average surface geometry, was used to analyse the effect on surface generation. Tables 3 and 4 give the results of ANOVA on surface roughness for two types of micro-end mills. All tabulated $F$ values $(\alpha=0.05)$ except two-level interactions of depth of cut in Table 4 and three-level interactions in Table 3 are smaller than the calculated values, which corresponds to a confidence level of $95 \%$ in evaluation of process parameters.
For both micro-tools, it was observed that there is no significant difference between the first set of slots (exp \#1) and validation slots (exp \#17) in terms of surface roughness and micro-surface morphology. Therefore, the tool wear effect is regarded negligible under this certain cutting distance in this work. Within the cutting parameter range used in the experiments, sub-micron-level surface roughness has been achieved by both tools. However, it can be seen from Table 2 and Figs. 6 and 7 that under the same cutting conditions, diamond-coated tools can achieve much better surface roughness. Minimum average surface roughness, $\mathrm{Ra}$, value of around $40 \mathrm{~nm}$ was measured at higher cutting speed and lower axial depth of cut when using diamond-coated tools, whilst maximum surface roughness, Ra, value of around $270 \mathrm{~nm}$ was measured at lower cutting speed and higher axial depth of cut when using CBN tools.

The ANOVA results show that for $\mathrm{CBN}$ tools, feedrate and depth of cut have a significant influence on surface roughness and they contribute 55.8 and $16.9 \%$ to overall response, respectively. For diamond-coated tools, both cutting speed and depth of cut have a significant influence on surface roughness and they contribute 40.1 and $22.8 \%$ to overall response, respectively. Feedrate is also expected to have influence on

Table 4 ANOVA for surface roughness, Ra, using CBN tools

\begin{tabular}{|c|c|c|c|c|c|c|c|}
\hline Source of variation & $\begin{array}{l}\text { Sum of squares } \\
\left(\times 10^{-3}\right)\end{array}$ & $\begin{array}{l}\text { Degrees of } \\
\text { freedom }\end{array}$ & $F$ (calculated) & $\begin{array}{l}F \text { (tabulated, } \\
\alpha=0.05)\end{array}$ & $P$ value & $\begin{array}{l}\text { Contribution } \\
\text { ratio } \%\end{array}$ & Result interpretation \\
\hline Feedrate (A) & 168.417 & 3 & 104.98 & 2.80 & 0.000 & 55.848 & Significant \\
\hline Cutting speed (B) & 2.903 & 1 & 5.43 & 4.04 & 0.024 & 0.997 & Not significant \\
\hline Depth of cut (C) & 50.681 & 1 & 94.78 & 4.04 & 0.000 & 16.954 & Significant \\
\hline $\mathrm{AB}$ & 31.189 & 3 & 19.44 & 2.80 & 0.000 & 10.305 & Not significant \\
\hline $\mathrm{AC}$ & 3.493 & 3 & 2.18 & 2.80 & 0.103 & 1.161 & Not significant \\
\hline $\mathrm{BC}$ & 0.013 & 1 & 0.02 & 4.04 & 0.876 & 0.432 & Not significant \\
\hline $\mathrm{ABC}$ & 18.456 & 3 & 11.50 & 2.80 & 0.000 & 6.135 & Not significant \\
\hline Error & 25.668 & 48 & & & & 8.533 & \\
\hline Total & 300.819 & 63 & & & & 100 & \\
\hline
\end{tabular}




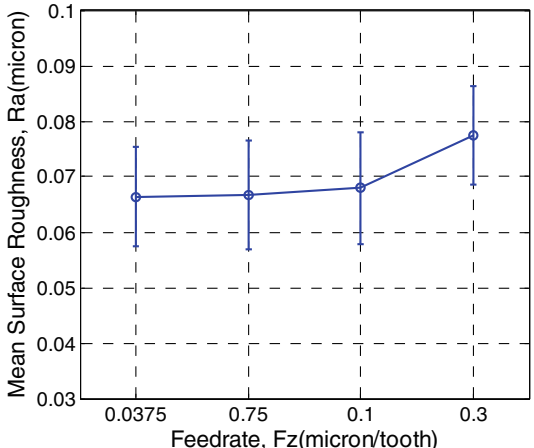

(a)

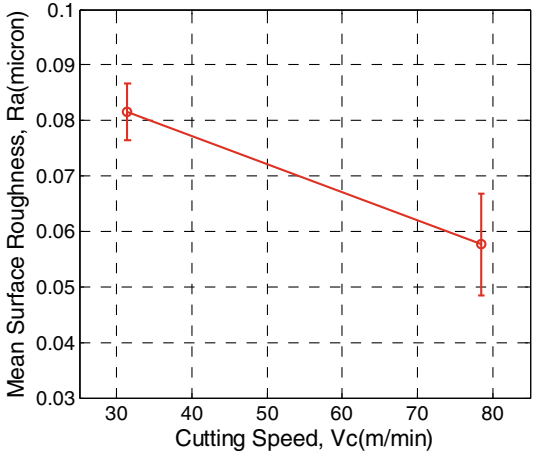

(b)

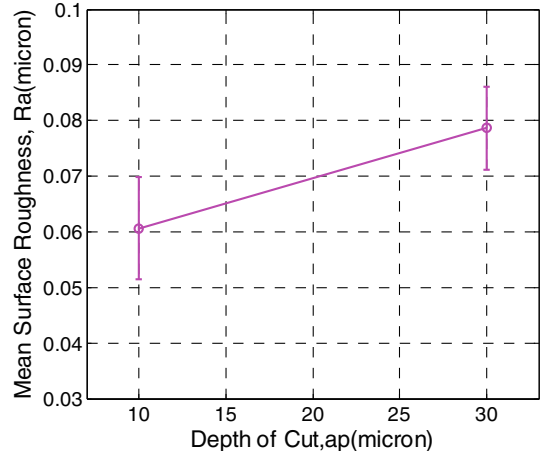

(c)

Fig. 6 Main effect plots for influences of single factors on surface roughness with diamond-coated micro-end mills: a feedrate, fz; b cutting speed, Vc; c axial depth of cut, $a_{\mathrm{p}}$

surface generation for diamond-coated tools, but its influence is hard to be interpreted from the ANOVA table statistically, so the influence will be discussed using the main effect plots.

Both the interaction between feedrate and cutting speed and the interaction between feedrate and depth of cut have effects on the measured surface roughness; however, these interaction effects are not significant as single-factor main effects. Three-level interactions are even more negligible; therefore, it is not worthwhile to examine the statistical significance of these effects.

Main effects in terms of mean Ra values are plotted in Figs. 6 and 7 to quantitatively assess the effect of each process parameters on micro-machining process. Similar to micromilling of ductile metallic materials, feedrate is normally believed to be a dominating factor affecting surface finish, i.e. an increase in feedrate results in an increase of surface roughness values, and this tendency is very pronounced for $\mathrm{CBN}$ tools as shown in Fig. 7a. But for diamond-coated tools, this tendency is not very clear. As shown in Fig. 6a, when feedrate is lower than a certain value, $0.15 \mu \mathrm{m} /$ tooth in this experiment, further reducing feedrate will not result in better surface roughness.

When cutting speed increases from 31.4 to $78.5 \mathrm{~m} / \mathrm{min}$, there is around $30 \%$ decrease in surface roughness value when using diamond-coated tool as shown in Fig. 6b, whilst only $7 \%$ decrease in surface roughness value was observed for CBN tools, as shown in Fig. 7b. This suggests that higher cutting speed hence higher machining efficiency can achieve better surface roughness especially for diamond-coated tools. Therefore, a higher spindle speed is desirable in micro-milling of silicon.

As expected, axial depth of cut has a negative influence on surface roughness, i.e. an increase in axial depth of cut will deteriorate surface finish. This tendency is noticeable for both tools, and there is around $30 \%$ increase in surface roughness value, when depth of cut increases from 10 to $30 \mu \mathrm{m}$.

Tool sharpness in terms of cutting edge radius is believed to have a positive influence on surface roughness, i.e. smaller tool edge radius is expected to result in better surface finish. Although the estimated tool edge radius of the diamondcoated tools and CBN are 6 and $3 \mu \mathrm{m}$, respectively, relatively 'blunt' diamond-coated tools can achieve superior surface. A close examination on the diamond-coated tool surface shows that the cutting tool surface was deposited diamond thin films which were controlled to have 'rough' faceted cutting edges as shown in Fig. 8. The faceted cutting edge can be considered as a grinding tool with abrasive grains which dimensions are

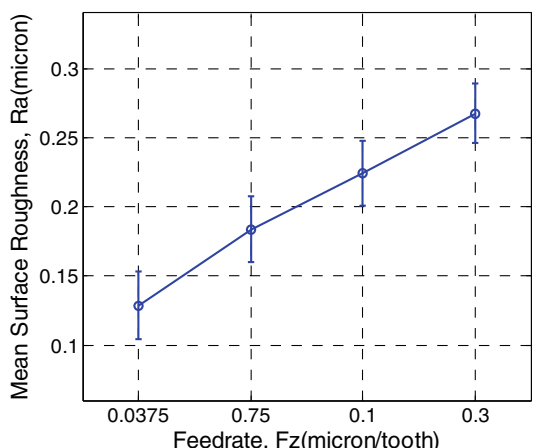

(a)

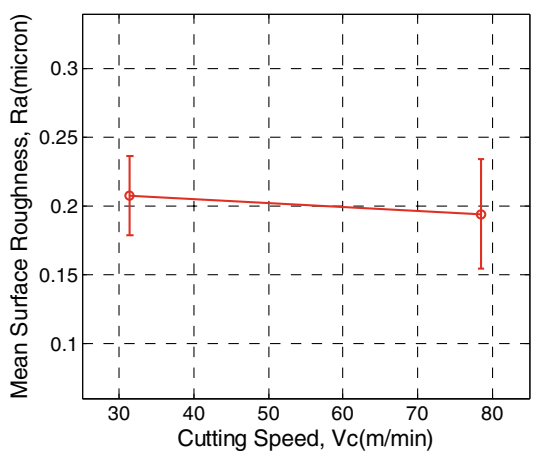

(b)

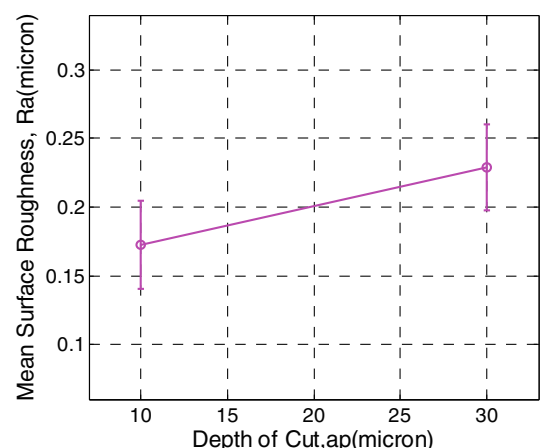

(c)

Fig. 7 Main effect plots for influences of single factors on surface roughness with CBN micro-end mills: a feedrate, fz; $\mathbf{b}$ cutting speed, Vc; $\mathbf{c}$ axial depth of cut, $a_{\mathrm{p}}$ 
Fig. 8 SEM micrograph of diamond-coated tool surface (new tool)

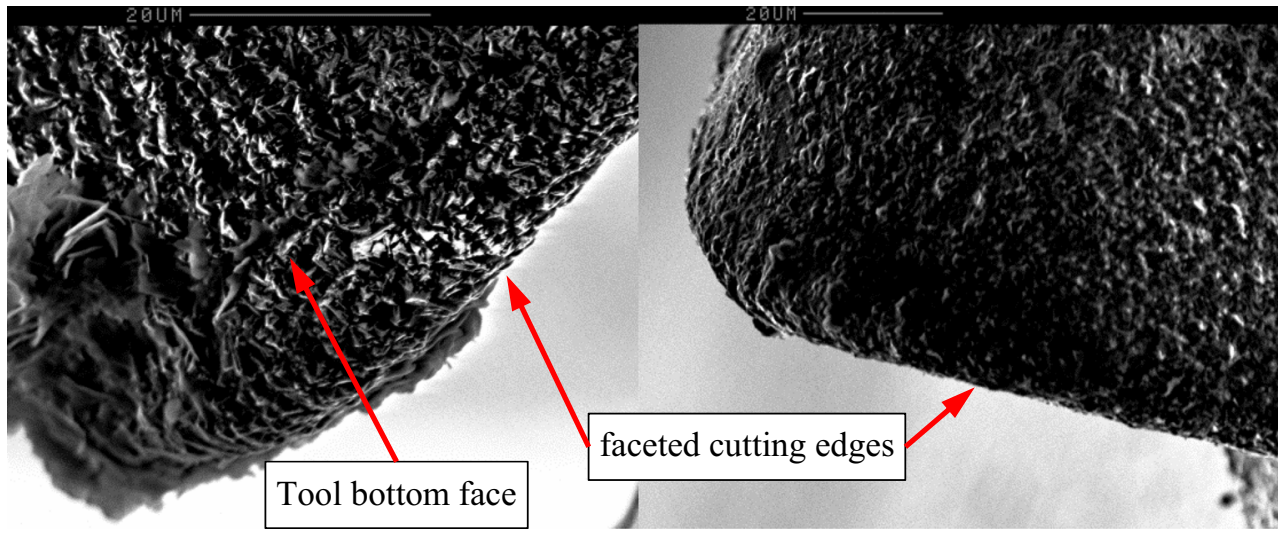

estimated to be at a sub-micron level. Compared with the diamond-coated tool, solid CBN micro-tools have a smooth tool surface. When a small feedrate is used, abrasive diamond machining may have taken place instead of cutting. Therefore, better surface roughness was achieved using diamond-coated tools in this experiment.

It should be noted that although brittle mode of cutting took place at some machining conditions, in particular when machining with $\mathrm{CBN}$ tools, the achievable surface roughness values are similar to those in micro-milling of metals under similar machine tool setup and machining conditions [8], although in some applications achieving a crack-free surface is more important than good surface roughness.

\subsection{Phase transformation and subsurface residual stress}

The Raman spectrum of silicon is well known, and a wide literature has been devoted to the phase transform of this material. Figure 9 shows typical Raman spectra on micro-end milled silicon surface. Absolute values of intensity from

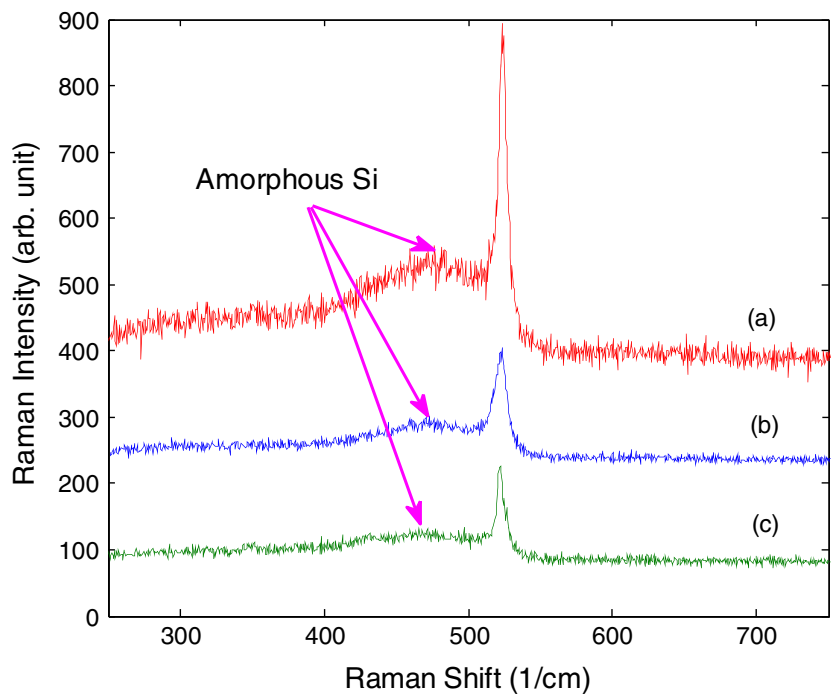

Fig. 9 Typical Raman peak shift measured on the bottom surface of the slots by diamond-coated tools. Cutting conditions: $a_{\mathrm{p}}=10 \mu \mathrm{m} ; \mathrm{Vc}=$ $31.4 \mathrm{~m} / \mathrm{min} ; \mathrm{fz}=$ (a) 0.0375 , (b) 0.075 , (c) $0.1 \mu \mathrm{m} /$ tooth different scans vary due to non-uniformity of the surface, e.g. surface roughness; therefore, a comparison of intensity is not meaningful for different spectra measurements. Crystalline to amorphous phase transformation was frequently observed in certain machining conditions. As discussed in Section 2, due to cutting edge radius size effect in micro-milling, large effective negative rake angle can create high hydrostatic pressure in the tool/workpiece interface. Therefore, this phase transformation is believed to be induced by the compressive pressure in the cutting zone. The presence of amorphous phase silicon provides evidence to the conclusions on ductile or partial ductile mode machining based on the surface morphology observation.

Other metastable phase transformations, such as Si-I cubic diamond structure to Si-III, IV, XII as reported in the literatures on polishing, grinding or dicing of single-crystal silicon [34], were not found in this experiment. This is because these phase transformations are normally temperature induced and under small depth of cut and feedrate in this experiment; temperature rise in the cutting zone was not high enough to induce these phase transformations.

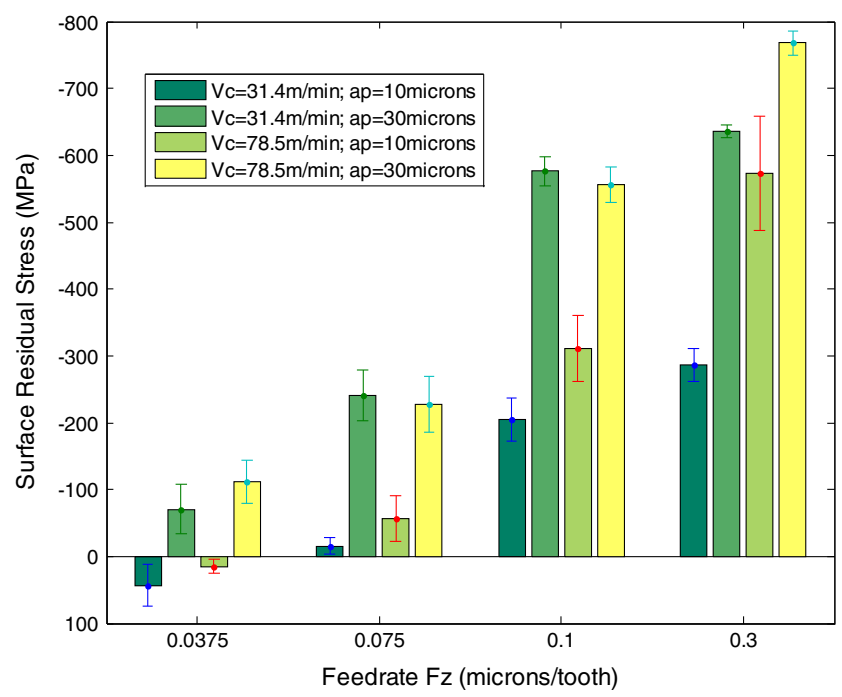

Fig. 10 Residual stress of micro-machined surface by diamond-coated tools 


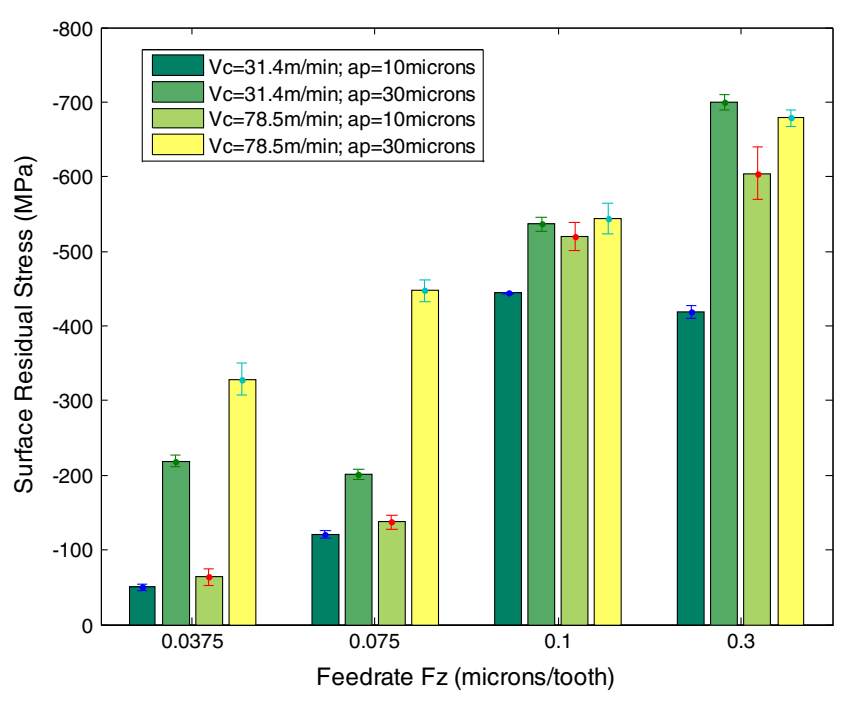

Fig. 11 Residual stress of micro-machined surface by $\mathrm{CBN}$ tools

Residual stresses will affect the performance of microproducts and therefore have to be controlled and minimised by appropriate treatments after mechanical processing. But the first step is to measure the residual stresses and find the correlations with machining parameters. An absolute value of residual stress can be determined by correlating the Raman shift in the peak wavenumber with the stress present. For unstrained pristine silicon where the Raman peak is centred at $520 \mathrm{~cm}^{-1}$, a stress sensitivity factor of $3.2 \mathrm{~cm}^{-1} \mathrm{GPa}^{-1}$ is used in this study [38], i.e. a shift of $3.2 \mathrm{~cm}^{-1}$ in Raman spectra peak corresponds to 1-GPa stress. Strain within the silicon lattice shifts the peak, with tensile stresses causing negative peak frequency shifts and compressive stresses causing positive peak frequency shifts.

Raman spectra shift shows that the residual stresses are compressive on most of the machined surface, which agrees with those reported in single-point diamond turning of silicon [35] and micro-scratching of silicon [39]. Figures 10 and 11 show the mean values of residual stress under various machining conditions. For both micro-tools, feedrate has the most significant influence on the magnitude of residual stress. Higher level of feedrate, cutting speed, and axial depth of cut results in higher residual stress. A maximum surface residual stress mean value of around $700 \mathrm{MPa}$ was measured at higher feedrate of $0.3 \mu \mathrm{m} /$ tooth and depth of cut of $30 \mu \mathrm{m}$ when using both micro-tools. At a very small feedrate $(0.0375 \mu \mathrm{m} /$ tooth $)$, residual stress status in micro-milled surface by diamond-coated tools is more complex. Both tensile and compressive stresses were observed, which can be attributed to grinding abrasive effect by the 'rough' faceted cutting edge of the diamondcoated tools. However, the tensile stress status is in agreement with the lapped surfaces of Si wafer and dicing of silicon [34].

It should be noted that large variations were observed in the magnitude of residual stress, especially for diamond-coated tool machined surface. This is mainly because surface defects make the residual stress level non-uniformly distributed. Therefore, the residual stresses measured are not very statistically confident. A surface residual stress mapping covering the whole surface will be needed for future research to characterise the correlation between stress level and surface defects.

\section{Application perspectives}

Applications of micro-machined silicon components are of abundance with growing interest in areas such as medical. An example of medical application is the development of opto-electrode for neuroimplantation. Such application allows necessary electronics to be overlaid on both silicon surfaces to allow recordings and control of neural activities. Figure 12 shows an example of the opto-electrode profile machined using micro-milling. The opto-electrode profile shown in Fig. 12 was micro-milled with reasonably optimised cutting parameters to a depth of approximately $100 \mu \mathrm{m}$. From Fig. 12, the side edges that resulted from machining show potential in employing micro-milling on silicon since no visible edge defects were observed. Although the method of micro-milling on silicon is feasible, however, research on improved machining parameters for silicon is required. This is because functional applications especially in the medical area require more complex profiles involving the micro-machining of fracturefree silicon components with a higher aspect ratio.
Fig. 12 Example of micromachined silicon component

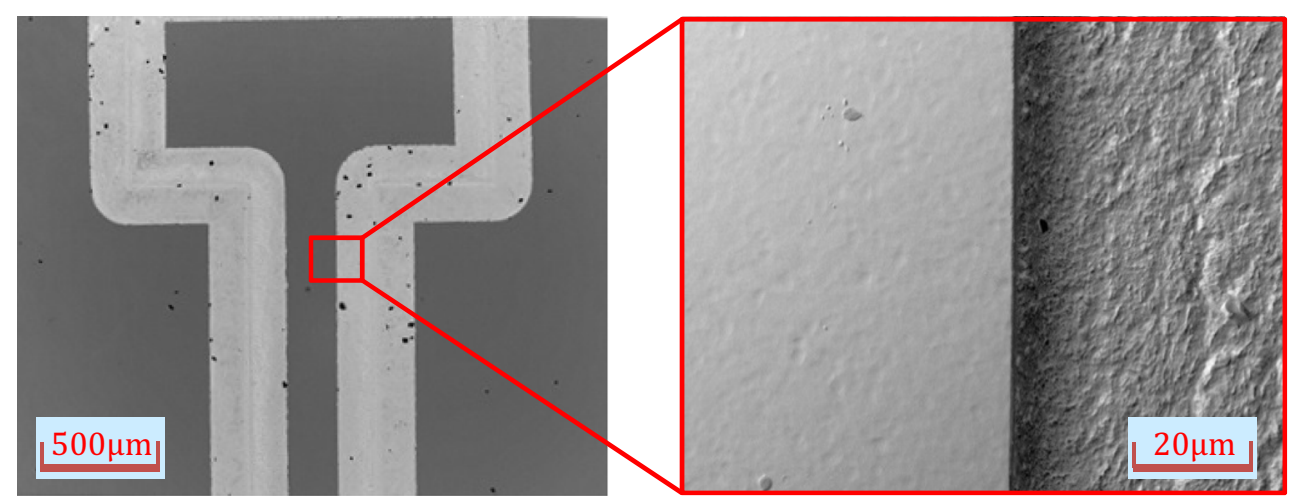




\section{Conclusions}

Micro-machining of monocrystalline silicon was performed by micro-end milling process using diamond-coated and $\mathrm{CBN}$ tools. The following conclusions can be drawn from this work:

- Surface roughness of a few tens of nanometers on monocrystalline silicon can be achieved by micro-milling using diamond-coated end mills. Higher spindle speed, smaller depth of cut and modest feedrate were found to achieve good surface finish.

- Surface topography analysis and the presence of amorphous phase silicon on the machined surface show that the primary material removal mode is ductile or partial ductile, especially when lower feedrate and smaller depth of cut were used. Diamond-coated tools are more apt to produce a defect-free surface.

- Compressive subsurface residual stress was measured on most of the micro-machined surface, although tensile residual stress was measured when diamond-coated tools were used at a very small feedrate $(0.0375 \mu \mathrm{m} /$ tooth $)$.

- Machining-induced interior type edge chipping defects were observed on the slot edges, predominantly in down milling side of the slot. Under the same cutting conditions, diamondcoated tools tend to produce lesser edge chipping defects than CBN tools. Modest depth of cut of less than $10 \mu \mathrm{m}$ should be maintained to achieve chipping-free edge quality.

This research has demonstrated that micro-milling offers a promising alternative fabrication route to clean room approaches for fabrication of silicon components at a few tens to a few hundreds of micron scale. The results are also expected to be useful for micro-cutting of other brittle materials, such as germanium, lithium niobate, silicon carbide, glass, etc.

Acknowledgments The authors wish to thank the Engineering and Physical Sciences Research Council (EP/M020657/1) and Visiting Scholar Foundation of the State Key Lab. of Mechanical Transmission in Chongqing University for the support for this work. The authors are also grateful to Jamie Hodgson, Ben Walker and Isabel Arce-Garcia for their assistance in the work.

\section{References}

1. Ehmann KF, Bourell D, Culpepper ML, Hodgson TJ, Kurfess TR, Madou M, Rajurkar K, De Vor RE (2005) International assessment of research and development in micromanufacturing. World Technology Evaluation Center, Baltimore

2. Huo D, Cheng K, Wardle F (2010) Design of a five-axis ultraprecision micro-milling machine-UltraMill. Part 1: holistic design approach, design considerations and specifications. Int J Adv Manuf Technol 47:867-877

3. Cheng K, Huo D (2013) Micro cutting: fundamentals and applications. Wiley, Chichester
4. Newby G, Venkatachalam S, Liang SY (2007) Empirical analysis of cutting force constants in micro-end-milling operations. J Mater Process Technol 192-193: 41-47

5. Ng CK, Melkote SN, Rahman M, Senthil KA (2006) Experimental study of micro- and nano-scale cutting of aluminum 7075-T6. Int J Mach Tools Manuf 46:29-936

6. Lee K, Dornfeld DA (2002) An experimental study on burr formation in micro milling aluminum and copper. Trans North Am Manuf Res Inst 30:255-262

7. Filiz S, Conley CM, Wasserman MB, Ozdoganlar OB (2007) An experimental investigation of micro-machinability of copper 101 using tungsten carbide micro-endmills. Int J Mach Tools Manuf 47:1088-1100

8. Huo D, Cheng K (2010) Experimental investigation on micromilling of oxygen-free, high-conductivity copper using tungsten carbide, chemistry vapour deposition, and single-crystal diamond micro tools. Proc Inst Mech Eng B J Eng Manuf 224:9951003

9. Rahman M, Kumar SA, Prakash JRS (2001) Micro milling of pure copper. J Mater Process Technol 116:39-43

10. Ozel T, Thepsonthi T, Ulutan D, Kaftanoglu B (2011) Experiments and finite element simulations on micro-milling of Ti-6 Al-4V. Ann CIRP 60:85-88

11. Schueler GM, Engmann J, Marx T, Haberland R, Aurich JC (2010) Burr formation and surface characteristics in micro-endmilling of titanium alloys. In: Aurich JC, Dornfeld D (eds) Burrs - Analysis, Control and Removal. Springer, Berlin, pp 129-138

12. Weule H, Hüntrup V, Tritschler H (2001) Micro-cutting of steel to meet new requirements in miniaturization. Ann CIRP 50:61-64

13. Bissacco G, Hansen HN, Chiffre LD (2005) Micromilling of hardened tool steel for mould making applications. J Mater Process Technol 167:201-207

14. Huo D, Lin C, Dalgarno K (2014) An experimental investigation on micro machining of fine-grained graphite. Int J Adv Manuf Technol 2004(72):943-953

15. Nakamoto K, Katahira K, Ohmori H, Yamazaki K, Aoyama T (2012) A study on the quality of micro-machined surfaces on tungsten carbide generated by PCD micro end-milling. Ann CIRP 61: $567-570$

16. Friedrich CR, Vasile MJ (1996) Development of the micromilling process for high-aspect-ratio microstructures. J Microelectromech Syst 5:33-38

17. Ogilvie IRG, Sieben VJ, Floquet CFA, Zmijan R, Mowlem MC, Morgan H (2010) Reduction of surface roughness for optical quality microfluidic devices in PMMA and COC. J Micromech Microeng 20:1-8

18. Cho MW, Kim DW, Cho WS (2007) Analysis of micro-machining characteristics of Si3N4-hBN composites. J Eur Ceram Soc 27: $1259-1265$

19. Rusnaldy, Jo Ko T, Kim HS (2007) Micro-end-milling of singlecrystal silicon. Int J Mach Tools Manuf 47:2111-2119

20. Rusnaldy, Jo Ko T, Kim HS (2008) An experimental study on microcutting of silicon using a micromilling machine. Int $\mathrm{J}$ Adv Manuf Technol 39:85-91

21. Arif M, Rahman M, San WK (2012) An experimental investigation into micro ball end-milling of silicon. J Manuf Process 14:52-61

22. Arif M, Rahman M, San WY, Doshi N (2011) An experimental approach to study the capability of end-milling for microcutting of glass. Int J Adv Manuf Technol 53:1063-1073

23. Foy K, Wei Z, Matsumura T, Huang Y (2009) Effect of tilt angle on cutting regime transition in glass micromilling. Int $\mathrm{J}$ Mach Tools Manuf 49:315-324

24. Li XP, Cai MB, Rahman M (2010) Study of the upper bound of tool edge radius in nanoscale ductile mode cutting of silicon wafer. Int $\mathrm{J}$ Adv Manuf Technol 48:993-999 
25. Yan JW, Asami T, Harada H (2009) Fundamental investigation of subsurface damage in single crystalline silicon caused by diamond machining. Precis Eng 33:378-386

26. Blake PN, Scattergood RO (1990) Ductile-regime machining of germanium and silicon. J Am Ceram Soc 73:949-957

27. Leung TP, Lee WB, Lu XM (1998) Diamond turning of silicon substrates in ductile regime. J Mater Process Technol 73:42-48

28. Chao CL, Ma KJ, Liu DS, Bai CY, Shy TL (2002) Ductile behaviour in single-point diamond-turning of single-crystal silicon. J Mater Process Technol 127:187-190

29. Cheng J, Gong YD (2014) Experimental study of surface generation and force modeling in micro-grinding of single crystal silicon considering crystallographic effects. Int J Mach Tools Manuf 77:1-15

30. Tanaka H, Shimada S, Ikawa N (2004) Brittle-ductile transition in monocrystalline silicon analyzed by molecular dynamics simulation. Proc Inst Mech Eng C J Mech Eng Sci 218:582-590

31. Cai M, Li X, Rahman M (2007) Molecular dynamics modeling and simulation of nanoscale ductile cutting of silicon. Int J Comput Appl Technol 28:2-8

32. Hu ZX, Hedley J, Gallacher BJ, Arce-Garcia I (2008) Dynamic characterization of MEMS using Raman spectroscopy. J Micromech Microeng 18(9):1-10

33. Wermelinger T, Borgia C, Solenthaler C, Spolenak R (2007) 3-D Raman spectroscopy measurements of the symmetry of residual stress fields in plastically deformed sapphire crystals. Acta Mater 55:4657-4665

34. Gogotsi Y, Baek C, Kirscht F (1999) Raman microspectroscopy study of processing-induced phase transformations and residual stress in silicon. Semicond Sci Technol 14(10):936-944

35. Jasinevicius RG, Duduch JG, Montanari L, Pizani PS (2008) Phase transformation and residual stress probed by Raman spectroscopy in diamond-turned single crystal silicon. Proc Inst Mech Eng B J Eng Manuf 222:1065-1073

36. Gong H, Fang FZ, Zhang XF, Du J, Hu XT (2013) Study on the reduction strategy of machining-induced edge chipping based on finite element analysis of in-process workpiece structure. J Manuf Sci Eng 135:011017-011017-10

37. Ng SJ, Le DT, Tucker SR, Zhang G (1996) Control of machining induced edge chipping on glass ceramics. Techn Res Rep No. TR 1996-3

38. Lucazeau G, Abello L (2002) Micro-Raman analysis of residual stresses and phase transformations in crystalline silicon under micro indentation. J Mater Res 12:2262-2273

39. Gogotsi Y, Zhou G, Ku SS, Cetinkunt S (2001) Raman microspectroscopy analysis of pressure-induced metallization in scratching of silicon. Semicond Sci Technol 16:345-352 